\title{
latrogenias farmacológicas provocadas por medicamentos usados durante a Parada Cardiorrespiratória: revisão narrativa
}

\author{
Pharmacological atrogenies caused by drugs used during Cardiorespiratory Arrest: \\ narrative review
}

\author{
latrogénesis farmacológica causada por fármacos utilizados durante el Paro \\ Cardiorrespiratorio: revisión narrativa
}

Eliseba dos Santos Pereira ${ }^{1 *}$, Luciano da Silva Lopes ${ }^{2}$, Eliel dos Santos Pereira ${ }^{3}$.

\begin{abstract}
RESUMO
Objetivo: Apresentar as principais complicações das drogas utilizadas durante uma Parada Cardiorrespiratória (PCR) e as condutas de assistências advindas desse uso. Revisão Bibliográfica: A PCR constitui um dos maiores desafios para a equipe de profissionais de saúde no ambiente hospitalar. Vários procedimentos são realizados com o objetivo de manter as funções cardiorrespiratórias do paciente. Dentre estes importantes procedimentos estão sendo realizados a administração de medicamentos que contribui para o reestabelecimento das funções vitais do paciente. Dessa forma, torna-se importante que as propriedades farmacológicas desses medicamentos sejam conhecidas para que se possa entender os efeitos esperados e as iatrogenias ou complicações advindas desse uso. As drogas encontradas como úteis durante uma PCR foram a adrenalina, vasopressina, amiodarona, lidocaína e sulfato de magnésio. Todas essas substâncias apresentam características próprias quanto ao seu uso e possibilidade de provocar efeitos adversos, como problemas no sistema nervoso periférico e problemas cardiovasculares. Dentro do mesmo, foi ressaltado os procedimentos e cuidados que deve ter com paciente em PCR. Considerações Finais: A equipe de enfermagem precisa estar atenta para o conhecimento dessas complicações, assim como a sua identificação para que possa melhorar ainda mais a assistência dos pacientes com esta condição tão desafiadora que é a PCR.
\end{abstract}

Palavras-chave: Parada cardiorrespiratória, Medicamentos, Enfermagem.

\begin{abstract}
Objective: To present the main complications of the drugs used during a CPA and how to conduct assistance from this use. Bibliographic review: Cardiorespiratory Arrest (PCR) is one of the greatest challenges for the team of health professionals in the hospital environment. Several procedures are performed with the aim of maintaining the patient's cardiorespiratory functions. Among these important procedures, medication administration is being performed, which contributes to the restoration of the patient's vital functions. Thus, it is important that the pharmacological properties of these drugs are marked in order to understand the expected effects and the iatrogenies or complications arising from this use. The drugs found to be useful during a PCR were adrenaline, vasopressin, amiodarone, lidocaine and magnesium sulfate. All of these substances have their own characteristics regarding their use and the possibility of causing adverse effects, such as peripheral nervous system and cardiovascular problems. Within it, the procedures and care that should be taken with the patient in PCR were highlighted. Final Considerations: The nursing team needs to be attentive to the knowledge of these complications, as well as their identification so that it can further improve the care of patients with this condition so challenging that it is a CRP.
\end{abstract}

Key words: Cardiorespiratory arrest, Medications, Enfermagem.

\section{RESUMEN}

Objetivo: Presentar las principales complicaciones de los fármacos utilizados durante un CPA y cómo realizar la asistencia a partir de este uso. Revisión bibliográfica: El Paro Cardiorrespiratorio (PCR) es uno de los mayores desafíos para el equipo de profesionales de la salud en el ámbito hospitalario. Se realizan varios

\footnotetext{
${ }^{1}$ Hospital Universitário da Universidade Federal do Piauí. Teresina - PI. *E-mail: elisebassp@gmail.com

2 Programa de pós-graduação em biotecnologia (Renorbio) da Universidade Federal do Piauí (UFPI), Teresina - PI.

${ }^{3}$ Universidade Estadual do Maranhão, Grajau - MA.
} 
procedimientos con el objetivo de mantener las funciones cardiorrespiratorias del paciente. Entre estos importantes procedimientos, se está realizando la administración de medicamentos, que contribuye al restablecimiento de las funciones vitales del paciente. Por tanto, es importante que se marquen las propiedades farmacológicas de estos fármacos para comprender los efectos esperados y las iatrogenias 0 complicaciones derivadas de este uso. Los fármacos que resultaron útiles durante una PCR fueron adrenalina, vasopresina, amiodarona, lidocaína y sulfato de magnesio. Todas estas sustancias tienen características propias en cuanto a su uso y la posibilidad de provocar efectos adversos, como problemas del sistema nervioso periférico y cardiovasculares. Dentro de ella se destacaron los procedimientos y cuidados que se deben tener con el paciente en PCR. Consideraciones finales: El equipo de enfermería debe estar atento al conocimiento de estas complicaciones, así como a su identificación para que pueda mejorar aún más la atención de los pacientes con esta condición tan desafiante que es un PCR.

Palabras clave: Parada cardiorrespiratório, Medicamentos, Enfermagem.

\section{INTRODUÇÃO}

Entende-se Parada Cardiorrespiratória (PCR) como uma condição na qual o indivíduo apresenta interrupção súbita e inesperada das funções vitais e que se caracteriza pela cessação dos batimentos cardíacos, ausência de movimentos respiratórios e ineficiência circulatória podendo resultar em morte súbita. No momento da ressuscitação, o tempo para o início das manobras relacionadas a reversão da parada cardiorrespiratória é de fundamental importância, pois um intervalo de 5 minutos sem oxigenação cerebral é suficiente para provocar lesões irreversíveis no órgão, por isso a agilidade é crucial no atendimento. É necessário ficar atentos a qualquer mudança no quadro clínico dos pacientes para recuperação e reversão desta situação (BARBOSA IS, 2018; OLIVEIRA S, et al., 2018).

Episódios de PCR são mais comuns em pacientes graves, hemodinamicamente instáveis, como por exemplo, em pacientes de unidade de terapia intensiva com diferentes quadros, tais como fibrilação ventricular, taquicardia ventricular sem pulso e assistolia estão associadas ao surgimento de PCR e sua gravidade. Uma equipe multiprofissional bem treinada e com domínio técnico é fundamental para um bom prognóstico do paciente. Estudos mostram que medidas adequadas realizadas em tempo hábil alcançam mais de $70 \%$ de sobrevida nos pacientes acometidos. Nesse contexto, o enfermeiro ocupa papel fundamental considerando que este profissional desempenha diferentes tarefas frente ao paciente sendo essencial desde o processo de identificação do evento, realização de manobras durante o processo de ressuscitação, assim como da administração de medicamentos e acompanhamento do paciente após a PCR (SILVA R, 2016; SANTANA LS, et al., 2015).

A equipe de enfermagem tem um papel fundamental participando da identificação de sinais e sintomas precursores de uma PCR, assim como nos cuidados após RCP. As atitudes e comportamentos dos enfermeiros influenciam na rapidez, tomada de decisão e o nível de atendimento do resto da equipe (PINHEIRO D, et al., 2018)

Com o objetivo de sistematizar e de diminuir erros nas condutas realizadas em pacientes em uma PCR, a American Heart Association (AHA) elabora e atualiza protocolos que devem ser utilizados normalmente baseados em um processo internacional de validação dessas condutas. Com relação ao tratamento da PCR e de acordo com as diretrizes da AHA, são utilizadas manobras de ressuscitação, uso de desfibrilador e diferentes medicamentos são utilizados. Cada um dos recursos tem indicação própria e peculiaridades quanto a sua utilização e complicações ou iatrogenias quando utilizados. Quanto aos medicamentos utilizados, particularidades são importantes considerando que melhoram a função do coração e do sistema circulatório. Cada um deles tem o seu momento de uso, além de um intervalo de dose a ser administrado após correta diluição, além de possíveis efeitos adversos que podem acometer o paciente (CANOVA JCM, 2015; BARROS ALB e CAVALCANTE AMR, 2017; BARBOSA IS, 2018; BARROS FRB e LUIS NETO M, 2018; DUFF JP, et al., 2018).

Este conhecimento deve envolver principalmente aspectos relacionados ao mecanismo de ação das drogas usualmente administradas, para que se possa compreender os efeitos observados e as reações 
adversas. A compreensão desses aspectos favorece o bom acompanhamento do paciente melhorando ainda mais a sua recuperação, o que é uma tarefa desenvolvida em grande parte pela equipe de enfermagem. Dessa forma, como o enfermeiro tem grande participação na realização dos procedimentos em pacientes com PCR, o conhecimento dos aspectos farmacológicos das drogas utilizadas facilitará bastante o entendimento do processo como um todo e assim contribuirá para a atenção mais adequada ao paciente (BARROS ALB e CAVALCANTE AMR, 2017; CANOVA JCM, 2015; LAFETÁ AFM, et al., 2015).

As substâncias medicamentosas utilizadas na PCR atuam interferindo no sistema nervoso periférico e ou diretamente em estruturas do sistema cardiovascular. Devido a própria complexidade desses componentes fisiológicos, assim como a grande quantidade de receptores e neurotransmissores envolvidos, nem sempre a compreensão dos efeitos dessas substâncias é simples ou acessível. No entanto, sua compreensão é fundamental para um maior entendimento e previsão das consequências após sua administração (KATZUNG B, 2017; BRUNTON L, et al., 2018).

O presente trabalho tem por objetivo realizar uma revisão com ênfase nos aspectos farmacológicos das drogas utilizadas durante uma parada cardiorrespiratória, considerando principalmente os mecanismos envolvidos no surgimento de complicações ou iatrogenias pelo uso dessas drogas e sua importância para a equipe de enfermagem.

\section{REVISÃO BIBLIOGRÁFICA}

\section{Efeitos das drogas durante a PCR}

O tratamento da PCR envolve uma série de procedimentos que são realizados pelo profissional de saúde, incluindo compressões torácicas, uso de desfibrilador, manutenção de vias aéreas e administração de medicamento. Todos estes procedimentos são complementares e obedecem a uma sistematização. As últimas recomendações e diretrizes, poucas drogas na verdade são utilizadas. Mesmo assim, torna-se importante para o profissional de enfermagem conhecer as propriedades farmacológicas dessas sustâncias para entender os seus efeitos após administração e as possíveis complicações ou iatrogênicas a partir de seu uso. As drogas utilizadas são a adrenalina (também chamada de epinefrina); vasopressina, amiodarona e lidocaína. Outro fato importante é que em casos de assistolia que tem ausência de atividade elétrica no coração, o tratamento são as compressões torácicas pois a desfibrilação é contraindicada nesse caso pois poderá desordenar o ritmo elétrico (DUFF JP, et al., 2018; LAFETÁ AFM, et al., 2015).

A primeira droga a ser utilizada é a adrenalina ou epinefrina. Do ponto de vista farmacológico é classificada como uma substância adrenérgica tem forte atuação no sistema cardiorrespiratório. Nos vasos sanguíneos atua em receptores próprios chamados de receptores alfa 1 e beta 2 . Atuar em receptores alfa 1, promove a ativação da musculatura lisa dos vasos de pequeno calibre como arteríolas através da vasoconstricção. Essa propriedade justifica a denominação de vasopressor atribuída a adrenalina. Este efeito vasopressor promove o aumento da resistência periférica dos vasos, levando a aumento do retorno venoso e da perfusão cerebral e das coronárias. O efeito em receptores beta 2 promove vasodilatação em vasos de maior calibre, como por exemplo, nos músculos esqueléticos. Este efeito leva a uma diminuição da resistência periférica e isso impede o surgimento de valores pressóricos mais elevados no paciente. No entanto, a propriedade de aumento do retorno venoso não é comprometida e este efeito é importante porque ajuda a manter as funções do sistema cardiovascular que foram comprometidas durante uma PCR, justificando seu uso nessa condição (BRUNTON L, et al., 2018).

No coração, a adrenalina também apresenta efeito potente. Atua especificamente em receptores beta 1 . Ao ativar estes receptores, a adrenalina promove aumento da atividade elétrica do músculo cardíaco facilitando assim, o aumento da frequência (efeito cronotrópico) processo de contração (efeito inotrópico) do miocárdio. Essa propriedade é fundamental para reestabelecimento das funções do coração e juntamente com o aumento do retorno venoso, contribui sobremaneira para a sobrevida de um paciente após uma PCR. A dose de adrenalina nessa condição é de $1 \mathrm{mg}$ por via intravenosa ou intraóssea a cada 3 ou 5 minutos. Essa dose é a recomendada em situações em que o paciente apresenta fibrilação ventricular (FV) (BRUNTON L, et al., 2018). 
A vasopressina é outra substância que pode ser utilizada substituindo a adrenalina na primeira ou segunda dose em pacientes com PCR. A vasoconstricção promovida pela substância ocorre devido a ativação de receptores próprios chamados de receptores V1. Quando ativados, promovem vasoconstrição e efeitos semelhantes a adrenalina com aumento do retorno venoso e do fluxo sanguíneo nas coronárias e cerebral. No entanto, diferente da adrenalina não atua em receptores no coração e dessa forma seu efeito nesse órgão ocorre indiretamente apenas devido ao aumente do retorno venoso. É usada na dose de $40 \mathrm{UI}$ por via intravenosa. A administração de drogas vasoativas, como colocado anteriormente, melhora as funções cardiovasculares no paciente após uma PCR. Isso é importante para equipe de enfermagem, pois, o conhecimento dessas propriedades facilita o entendimento da evolução do paciente durante o processo melhorando a assistência ao paciente (BRUNTON L, 2018; KNY KT, 2018; AVNI T, et al., 2015).

As drogas antiarrítmicas, diferentes das drogas vasopressoras, são utilizadas como coadjuvantes. Paciente com fibrilação ventricular e taquicardia ventricular podem se beneficiar da utilização dessas drogas. Existem algumas controvérsias quanto aos benefícios, no entanto, as últimas diretrizes estabelecem seu uso naqueles pacientes não responsivos a desfibrilação. As drogas usadas são a amiodarona e a lidocaína. $\mathrm{A}$ lidocaína é considerada atualmente como uma alternativa a amiodarona (COSIN-SALES J e OLALLA JJ, 2016; SAINT-GERONS J, et al., 2016).

As drogas antiarrítmicas são divididas em grupos. A amiodarona pertence ao grupo III devido a suas propriedades de bloquear os canais de potássio nas células do miocárdio ou cardiomiócito. É uma droga com amplo espectro de ação antiarrítmico e por isso pode ser usada em diferentes tipos de arritmias. O seu mecanismo principal envolve o bloqueio de canais de potássio, porém, estudos mostram que além disso, bloqueia canais de sódio inativos além de bloquear fracamente canais de cálcio e ativar receptores adrenérgicos. Estas propriedades fazem com que haja uma lentificação da frequência cardíaca e condução no nodo átrio ventricular. Na PCR é usada na dose de $5 \mathrm{mg} / \mathrm{kg}$ ou $300 \mathrm{mg}$ por via intravenosa ou intraóssea. Pode ainda ser administrada uma dose suplementar de $150 \mathrm{mg}$ intercalada com vasopressor. A manutenção após retorno de ritmo com pulso é de $1 \mathrm{mg}$ por minuto por 6 horas e $0,5 \mathrm{mg}$ por minuto por mais 18 horas (BRUNTON L, 2018; TAVARES MB, 2016; PRIORI SG, et al., 2016).

A lidocaína por sua vez, é um anestésico local que também apresenta propriedades de bloquear canais de sódio. Por este mecanismo pertence ao grupo I dos antiarrítmicos, subgrupo b. Atua também bloqueando receptores do glutamato do tipo NMDA. Normalmente a lidocaína é considerada droga de segunda escolha caso a amiodarona não esteja disponível. Para a sua utilização, recomenda-se a dose de 1 a $1,5 \mathrm{mg} / \mathrm{kg}$, EV. Quando há persistência da FV/TVSP, doses adicionais de 0,5 a 0,75 mg/kg podem ser administradas a cada 5 a 10 minutos, até uma dose máxima de $3 \mathrm{mg} / \mathrm{kg}$. Na ausência de contraindicações, a utilização profilática de lidocaína pode ser avaliada em determinadas situações particulares (ex. ao longo das atividades de translado médico emergencial) quando o tratamento de FV/TVSP recorrente pode ter potencial desafiador (MENDONÇA FT, 2017; PRIORI SG, et al., 2016).

Outra droga utilizada é o sulfato de magnésio que atua inibindo a liberação de neurotransmissores adrenérgicos do sistema nervoso autônomo por bloqueio de canais de cálcio, além disso é antagonista dos receptores do glutamato. Este mecanismo leva a diminuição do ritmo cardíaco e a sua normalização no eletrocardiograma. A administração dessa droga deve ser em pacientes adultos que apresentam torsades de pointes (ou seja, TV polimórfica associada a intervalo QT longo). A dose deve ser 1 a $2 \mathrm{~g}$, diluído em $10 \mathrm{~mL}$ de soro glicosado a 5\% (MENDONÇA FT, 2017; PRIORI SG, et al., 2016).

Outro ponto importante é atentar para a diluição correta dessas substâncias. Vale lembrar que no ambiente hospitalar a responsabilidade de administração de medicamentos é da equipe de enfermagem. Ademais, após o uso dessas substâncias e considerando os outros procedimentos realizados em pacientes com PCR, espera-se a recuperação do ritmo cardíaco e da função de bomba do coração, funções estas que são fundamentais para a vida do paciente. Após a abordagem dos aspectos farmacológicos das drogas utilizadas em uma PCR, menciona-se agora os aspectos relacionados a possibilidade da ocorrência de iatrogenias pelo uso dessas substâncias. Vale ressaltar que mesmo o paciente fazendo uso em doses padronizadas e por pouco intervalo de tempo, isso não isenta da ocorrência de complicações pelo uso dessas drogas (PINHEIRO D, 2018; ABREU DP, et al., 2015). 
A adrenalina por ser uma droga adrenérgica pode provocar grande estimulação de receptores adrenérgicos e isso pode levar a picos de pressão arterial elevada devido a estimulação de receptores alfa 1. Pela administração de intravenosa rápida é possível ainda o desenvolvimento de arritmias ventriculares, além de hemorragia cerebral em consequência de elevação aguda de pressão arterial. A literatura mostra que o uso prévio de drogas que bloqueiam receptores beta, como propranolol por exemplo, pode potencializar estes efeitos. Em caso de extravasamento, é possível a ocorrência de necrose no local da administração. Estas características obrigam a utilização da droga apenas por acesso central ou vaso calibroso. Outros problemas menores devido ao uso de adrenalina podem ocorrer. São eles inquietação, tremores e palpitação. Mas considerando a condição de uma PCR eles são bem menos importantes e ademais, desaparecem com o paciente em repouso no leito. Além disso, a solução de adrenalina não pode ser misturada com solução alcalina, pois, provoca inativação da substância. Quanto a vasopressina, a literatura mostra que efeitos adversos como arritmias, diminuição do débito cardíaco e angina podem ocorrer. No entanto, são raros dentro dos protocolos utilizados. Outros efeitos como náuseas, tremores, vertigens e sensação de pulsação na cabeça podem ocorrer, porém, sem grande importância frente ao quadro de uma PCR. Estudos mostram ainda que raros casos de broncoconstrição podem ocorrer, o que poderia ser uma desvantagem para pacientes asmáticos (KATZUNG B, 2017; AMADO J, et al., 2016).

Quanto a amiodarona, normalmente é tida como uma droga que pode levar a vários problemas ou iatrogenias após a sua utilização. No entanto, a maioria das complicações com o uso dessa substância ocorrem após longo período de utilização. O efeito adverso mais importante é a fibrose pulmonar e desenvolvimento de arritmias. Porém, como dito anteriormente são efeitos que se manifestam apenas em tratamento prolongados, tento então menor importância durante o seu uso em uma PCR. Quanto ao seu uso intravenoso, a complicação mais séria seria a ocorrência de hipotensão devido a vasodilatação que pode ocorrer. Além disso, segundo a literatura, é frequente a diminuição do desempenho do miocárdio (PRIORI SG, et al., 2016).

É importante que a equipe de enfermagem atente para as possíveis complicações após uso da lidocaína. Após o uso de doses elevadas por via intravenosa pode ocorrer convulsões, tremores, disartria e grave comprometimento da consciência. Pode ainda ocorrer hipotensão, choque devido ao seu uso intravenoso, além de flebite em caso de extravasamento. Atentar para a ocorrência de nistagmo, pois pode ser forte indicador de toxicidade pela lidocaína (MENDONÇA FT, et al., 2017).

Como colocado anteriormente, o sulfato de magnésio é uma droga utilizada apenas em condições bem específicas durante uma PCR. Semelhante à lidocaína, o sulfato de magnésio também pode levar a um quadro de vasodilatação e assim provocar queda de pressão arterial. Além disso, devido a efeitos antagônicos ao cálcio, pode provocar diminuição de reflexos e até relaxamento do diafragma, agravando os movimentos da musculatura respiratória (MENDONÇA FT, et al., 2017; IRAZUZTA JE e CHIRIBOGA N, 2017).

Ressalta-se que muitos desses efeitos adversos provocados pelo uso de drogas durante ou logo após uma PCR, são considerados menos importantes quando comparados com a própria parada. No entanto, alguns podem agravar ou mesmo retardar a franca recuperação do paciente, ou mesmo, precisarão de tratamento ou condução. Dessa forma, a equipe de enfermagem precisa estar atenta para o conhecimento dessas complicações, assim como a sua identificação para que possa melhorar ainda mais a assistência dos pacientes com esta condição tão desafiadora que é a PCR (PINHEIRO D, 2018).

\section{Procedimentos Avançados realizados a PCR}

Existe uma sequência de atendimento que deve ser realizada ao paciente com ritmo de fibrilação ventricular (FV) ou taquicardia ventricular sem pulso TVSP ao monitor cardíaco. As condutas iniciam-se no pedido do afastamento das pessoas presentes para certificação de que não é encontrado o alto fluxo de oxigênio inspecionando o tórax. Em seguida, desfibrilar com choque único com a potência máxima de $360 \mathrm{~J}$ no monofásico (dois condutores elétricos) e $200 \mathrm{~J}$ no bifásico (três condutores elétricos). Depois disso, reiniciar a ressuscitação cardiopulmonar $(\mathrm{RCP})$ que é composta por compressões torácicas de alta qualidade e insuflações, que consiste em 30 Compressões e 2 Insuflações por cinco ciclos ou 100/120 compressões por minutos. Consequentemente, será preciso a administração de epinefrina $1^{\circ}$ dose $(300 \mathrm{mg}$ endovenosa 
$+20 \mathrm{~mL}$ de solução salina $0,9 \%$ ), já na segunda dose pode ser administrada após 3 a 5 minutos de $150 \mathrm{mg}$. Depois de já ter realizado simultaneamente o acesso venoso; após os cinco ciclos checar o ritmo, no caso da continuação dos ritmos FV ou TVSP, deve-se reiniciar todas as sequências (BRASIL, 2016).

É necessário esclarecer vários pontos sobre o uso das drogas, em muitos atendimentos na ausência de amiodarona, administra-se lidocaína 1 a $1,5 \mathrm{mg}$ pela via intravenosa. Existe também os casos de PCR secundária a hipomagnesemia ou taquicardia ventricular polimórfica que é recomendado o sulfato de magnésio. É notório ainda o embasamento sobre a noradrelina, dopamina ou dobutamina apesar de serem solicitadas caso o paciente venha ser reanimado deve-se ser administrada para manter estáveis as condições hemodinâmicas do paciente (BRASIL, 2016).

\section{Cuidados pós- PCR}

Inicialmente, encaminhar o paciente para um hospital apropriado ou UTI é o mais necessário, porque depois que o paciente tiver sido atendido por todo o suporte Básico e/ou avançado, ele irá precisar de cuidados maiores e mais precisos; É essencial controlar a temperatura para otimizar a recuperação neurológica, evitando que o paciente venha a desenvolver um quadro de febre e consequentemente outras complicações como desenvolver arritmias ou convulsões; Caso o paciente venha desenvolver um quadro de hipoglicemia e hiperglicemia é necessário estabilizar, pois se sabe que a hipoglicemia (quando os níveis de glicose no sangue estão abaixo do mínimo ideal, pode causar convulsões e até mesmo levar a óbito; Já a hiperglicemia (quando os níveis de glicose no sangue estão elevados do mínimo ideal), que pode causar Acidente Vascular Encefálico (AVE), Infarto, arritmias cardíacas graves (NASCIMENTO K, 2018).

\section{CONSIDERAÇÕES FINAIS}

Algumas dessas drogas abordadas podem agravar o quadro do paciente retardando a recuperação. Dessa forma, a equipe de enfermagem precisa estar atenta para o conhecimento dessas complicações, assim como a sua identificação para que possa melhorar ainda mais a assistência dos pacientes com esta condição tão desafiadora que é a PCR. Além disso necessita-se de um atendimento de alta qualidade e na pós reanimação do paciente realizar todos os procedimentos cabíveis. A parada cardiorrespiratória ou PCR é uma condição sempre desafiadora para a equipe multiprofissional de assistência ao paciente. A enfermagem tem um papel fundamental dentro do processo assistencial considerando que participa de todas as etapas desde a identificação, condutas e acompanhamento do paciente. Dessa forma, é esclarecido o porquê da importância do conhecimento das mesmas, mesmo sendo o uso de medicamentos uma ferramenta importante. Conhecer as propriedades farmacológicas das drogas utilizadas, assim como as complicações ou iatrogenias torna 0 profissional de enfermagem mais capacitado para esta tarefa.

\section{REFERÊNCIAS}

1. ABREU DP, et al. Responsabilidades éticas e legais do enfermeiro em relação à administração de medicamentos para pessoas idosas. Revista de Enfermagem do Centro-Oeste Mineiro, 2015; 3(5): 1905-1914.

2. AMADO J, et al. Choque cardiogénico - fármacos inotrópicos e vasopressores. Revista Portuguesa de Cardiologia, 2016; 35(12): 681-695.

3. AVNI T, et al. Vasopressors for the Treatment of Septic Shock: Systematic Review and Meta-Analysis. Public Library of Science One, 2015; 10(8): 1-17.

4. BARBOSA IS, et al. O conhecimento do profissional de enfermagem frente à parada cardiorrespiratória segundo as novas diretrizes e suas atualizações. Revista de Divulgação Científica Sena Aires, 2018; 2(7): 117-126.

5. BARROS ALB, CAVALCANTE AMR. Nursing in cardiology: state of the art and frontiers of knowledge. Revista Brasileira de Enfermagem, 2017; 70(3): 451-452.

6. BARROS FRB, LUIS NETO M. Parada e reanimação cardiorrespiratória: conhecimento do enfermeiro baseado nas diretrizes da American Heart Association 2015. Enfermagem em foco, 2018; 9(3): 8-12.

7. BRASIL. Ministério da Saúde. In: Protocolos de Intervenção para o SAMU 192 - Serviço de Atendimento Móvel de Urgência. Brasília, $2^{\circ}$ ed., 2016; 1-638.

8. BRUNTON L, et al. Goodman and Gilman's - Manual of Pharmacology and Therapeutics. 13ำed. McGraw-Hill Medical, 2018.

9. CANOVA JCM, et al. Parada cardiorrespiratória e ressuscitação cardiopulmonar: vivências da equipe de enfermagem sob o olhar da técnica do incidente crítico. Revista de Enfermagem UFPE online, 2015; 9(3): 7095-103. 
10. COSIN-SALES J, OLALLA JJ. Tratamiento farmacológico de la fibrilación auricular. Antiarrítmicos y anticoagulantes orales. Revista Española de Cardiología Suplementos, 2016; 16(1): 33-39.

11. DUFF JP, et al. American Heart Association Focused Update on Pediatric Advanced Life Support: An Update to the American Heart Association Guidelines for Cardiopulmonary Resuscitation and Emergency Cardiovascular Care. Circulation, 2018; 138(23): 1-8.

12. GARCÍA-FUERTES D, et al. Drug-Induced Long-QT and Torsades de Pointes in Elderly Polymedicated Patients. Arquivos Brasileiros de Cardiologia, 2015; 106(2): 156-159.

13. IRAZUZTA JE, CHIRIBOGA N. Magnesium sulfate infusion for acute asthma in the emergency department. Jornal de Pediatria, 2017; 93(1): 19-25.

14. KATSUNG B. Farmacologia Básica e Clínica. 13ํed. Rio de Janeiro: Mcgraw-hill interamericana, 2017.

15. KNY KT, et al. Use of vasopressin in the treatment of refractory septic shock. Revista Brasileira de Terapia Intensiva, 2018; 30(4): 423-428.

16. LAFETÁ AFM, et al. Suporte avançado de vida na parada cardiorrespiratória: aspectos teóricos e assistenciais. Revista da Universidade Vale do Rio Verde, Três Corações, 2015; 13(1): 653-663.

17. MENDONÇA FT, et al. Os efeitos da lidocaína e do sulfato de magnésio na atenuação da resposta hemodinâmica à intubação orotraqueal: estudo unicêntrico, prospectivo, duplamente encoberto e aleatorizado. Brazilian Journal Of Anesthesiology, 2017; 67(1): 50-56.

18. MORALES-CANÉ I, et al. Epinephrine in cardiac arrest: systematic review and meta-analysis. Revista Latinoamericana de Enfermagem, 2016; 24: 1-13.

19. NASCIMENTO K. 2018. In: Atendimento de enfermagem na reanimação cardiopulmonar. Universidade Federal do Triângulo Mineiro (UFTM), 2018; 1-47.

20. OLIVEIRA S, et al. Parada cardiorrespiratória: conhecimento de profissionais de saúde em um hospital público. Revista Pesquisa em Fisioterapia, 2018; 8(1): 101-109.

21. PINHEIRO D, et al. Parada cardiorrespiratória: vigilância, prevenção e cuidados após PCR / Cardiorespiratoryarrest. Revista de Pesquisa: Cuidado é Fundamental Online, 2018; 10(2): 577-584.

22. PRIORI SG, et al. Guía ESC 2015 sobre eltratamiento de pacientes conarritmiasventriculares y prevención de la muerte súbita cardiaca. Revista Española de Cardiología, 2016; 69(2): 1-75.

23. SAINT-GERONS J, et al. Papel de los antiarrítmicos en las taquicardias ventriculares. Cardiocore, 2016; 51(3): 9598.

24. SANTANA LS, et al. A equipe multidisciplinar na atenção a pessoa em parada cardiorrespiratória: uma revisão de literatura. Ciência Et Praxis, 2015; 7(13): 49-54.

25. SILVA R, et al. Parada cardiorrespiratória e educação continuada em Unidade de Terapia Intensiva. Revista de Ciências Médicas, 2016; 3(25): 129-136.

26. TAVARES MB, et al. Distúrbios da função tireoidiana induzidos pela amiodarona. Salus Journal Of Health Sciences, 2016; 2(2): 39-47. 